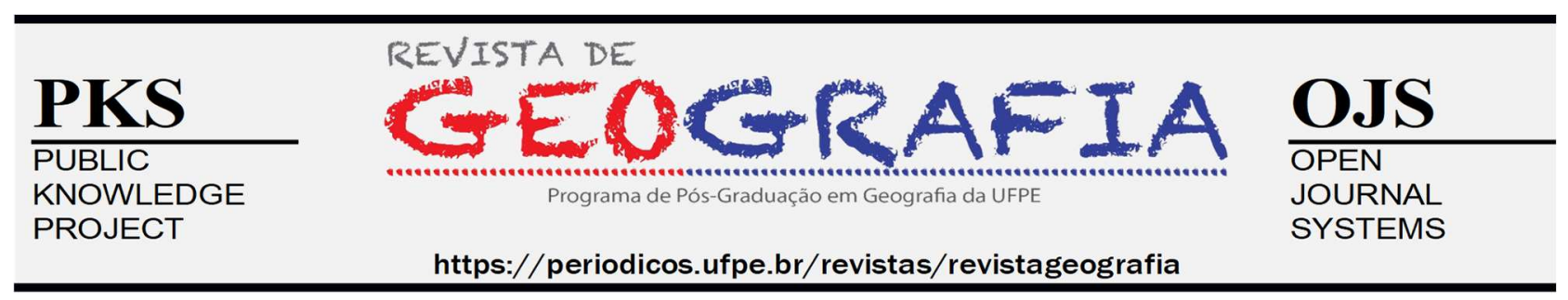

\title{
AVALIAÇÃO QUALI-QUANTITATIVA DA ARBORIZAÇÃO DAS PRAÇAS DA CIDADE DE ALMENARA - MG
}

\author{
Marival Pereira de Sousa ${ }^{1}$, Allívia Rouse Carregosa Rabbani², Maria Otávia Silva Crepaldi ${ }^{3}$, Arine \\ Barbosa Ferreira da Silva ${ }^{4}$

\begin{abstract}
${ }^{1}$ Programa de Pós-Graduação em Ciências e Tecnologias Ambientais (PPGCTA/UFSB/IFBA), Porto Seguro, Bahia. E-mail: marival.sousa@ifnmg.edu.br

${ }^{2}$ Instituto Federal de Educação, Ciência e Tecnologia da Bahia (IFBA), Porto Seguro, Bahia. E-mail: alliviarouse@ifba.edu.br

${ }^{3}$ Universidade Federal do Vale do São Francisco, Senhor do Bonfim, Bahia. E-mail: mariaotavia@gmail.com

4 Instituto Federal de Ciência e Tecnologia do Norte de Minas Gerais (IFNMG), Almenara, Minas Gerais. E-mail:
\end{abstract} \\ arinebarbosaf@gmail.com
}

Artigo recebido em 17/04/2020 e aceito em 21/06/2020

\begin{abstract}
RESUMO: Este trabalho analisou a composição florística e a estrutura fitossociológica de nove praças da cidade de Almenara (MG), a fim de diagnosticar a diversidade e a densidade da cobertura arbórea, bem como seus conflitos com o ambiente. A coleta dos dados foi realizada em forma de inventário quali-quantitativo simples de todas as árvores com altura total mínima de dois metros, observando os aspectos da condição da vegetação, a origem e porte, sanidade e dados dendrométricos, sendo calculados o diâmetro a altura do peito e da copa, frequência, densidade, cobertura e índice de Shannon-Weaver. Ao total, 221 árvores foram contabilizadas, distribuídas em 35 espécies e 16 famílias botânicas, das quais $44 \%$ são nativas. Dentre as espécies catalogadas destaca-se a Licania tomentosa (Benth.) Fritsch com 17,19\%. As praças apresentavam aspectos de relevância ambiental, com alta porcentagem de cobertura vegetal $(61,95 \%)$ e boa densidade média (114 ind/ha). Entretanto, há um baixo índice de diversidade de Shannon-Weaver (1,79 nats/ind), além de conflitos como obstrução da passagem de pedestres pelo afloramento de raízes, e a identificação de problemas de sanidade. Assim, existe falta de gestão desses espaços, visto que, medidas como substituição de espécies inadequadas e intensificação das práticas de manejo são necessárias.
\end{abstract}

Palavras-chave: Árvores; Espaços urbanos; Mobilidade.

\section{QUALITATIVE-QUANTITATIVE ASSESSMENT OF TREES IN SQUARES OF ALMENARA CITY (MINAS GERAIS STATES, BRAZIL)}

\begin{abstract}
This work analyzed the floristic composition and phytosociological structure of nine squares of the city of Almenara (MG), a diagnosis of diversity and density of tree cover, as well as their conflicts with the environment. Data collection was performed with the help of a technical form in the form of a simple qualitative and quantitative inventory of all trees (young and adult), with a minimum total height of two meters. Aspects of the condition of the tree vegetation, the origin and size of the species, health status and dendrometric data were observed, allowing calculations such as diameter at breast height, crown diameter, frequency, density, tree cover and Shannon-Weaver diversity index. There were 221 trees, distributed in 35 species and 16 botanical families, of which $44 \%$ are native to Brazil. Other cataloged species include Licania tomentosa (Benth.) Fritsch with $17.19 \%$. As the plots have aspects of environmental relevance, with high percentage of vegetation cover (61.95\%) and good average density (114 ind / ha). However, there is a low Shannon-Weaver diversity index (1.79 nats/ind), as well as conflicts such as obstruction of pedestrian crossing by root outcrops and identification of health problems. Thus, there is a lack of management of these spaces, as measures such as replacement of inappropriate species and intensification of management practices are necessary.
\end{abstract}

Keywords: Trees; Urban spaces; Urban mobility. 


\section{INTRODUÇÃO}

Conforme as cidades crescem, os efeitos decorrentes das mudanças de paisagem, por vezes, promovem desconforto entre os habitantes e a infraestrutura urbana. As pesquisas envolvendo a dinâmica das pequenas cidades têm ganhado novas proporções e interesses pela ciência geográfica, porém, ainda são poucos os estudos, pois o próprio conceito de cidade pequena ainda é discutido devido a dificuldade em caracterizá-la (MANFIO; BENADUCE, 2011).

$\mathrm{O}$ crescimento das cidades e a pressão antrópica em meados da segunda metade do século XX foram as causas dos grandes problemas de ordem socioambiental, dentre os quais se destaca a degradação de áreas naturais motivada pela ocupação das zonas urbanas sem planejamento (IMAM; BANERJEE, 2016). Assim, houve a necessidade da criação de espaços arborizados que possibilitassem melhor qualidade de vida à população (OLIVEIRA et al., 2013).

Espaços arborizados como praças, jardins públicos e parques, considerados como áreas verdes urbanas, podem fornecer diferentes funções, daquelas fornecidas por árvores plantadas no leito das vias públicas, pois além dos aspectos estéticos e ecológicos, proporcionam lazer e recreação, possibilitando a interrelação entre a sociedade e os valores ambientais e culturais, sem a interferência da maioria dos mobiliários urbanos (AlCANTARA; VAZQUEZ, 2015; SHANAHAN et al., 2015; RUBIRA, 2016).

Ali-Khodja (2010) ressaltou a presença de áreas verdes como imprescindíveis, dada à complexidade e o rigor que o ambiente construído apresenta, tendo, nessas áreas, a oferta de um local propício para o descanso e relaxamento, satisfação visual e estimulação intelectual. Além disso, outros benefícios podem ser elencados, como a diminuição da temperatura; controle da poluição sonora e atmosférica; aumento da umidade do ar; valorização da paisagem proporcionando melhor efeito estético, ambiental e psicológico aos habitantes; e contribuição para a manutenção da vida silvestre (CEMIG, 2011; VARGAS; BALMACEDA, 2011; PAGLIARI; DORIGON, 2013; GONÇALVES; MENEGUETTI, 2015; CESSA 2017; SCHVARSTZHAUPT; REIS, 2017).

A floresta urbana, com planejamento adequado, pode prover bem-estar ao desempenhar função significativa no sentido de tornar as nossas cidades melhor adaptadas aos rigores que esperamos de um clima em mudança. Contudo, esses espaços não recebem a devida atenção na maioria das cidades brasileiras, que são marcadas pela carência de áreas verdes, da arborização urbana das praças e parques, principalmente nas áreas centrais da cidade (RIVELINI; GOMES, 2017). Para que os benefícios das áreas verdes sejam alcançados, é necessário que a pesquisa científica adote abordagens interdisciplinares, visando melhor comunicação com o público 


\section{(LIVESLEY; MCPHERSON; CALFAPIETRA, 2016).}

Diante disso, o presente trabalho objetivou avaliar a arborização existente nas praças públicas da cidade de Almenara, interior de Minas Gerais, a fim de obter um diagnóstico das áreas verdes da cidade.

\section{MATERIAL E MÉTODOS}

A cidade de Almenara está localizada no nordeste do Estado de Minas Gerais (16 $11^{\prime}$ 01" Sul, $40^{\circ} 41^{\prime} 40^{\prime \prime}$ Oeste), na microrregião do Baixo Jequitinhonha, a uma distância de $744 \mathrm{~km}$ da capital Belo Horizonte. Sua população total estimada é de 38.775 habitantes; desse total, 7.025 , ou 20\% da população, são residentes na zona rural e o restante, $31.020(80 \%)$ são correspondentes à população urbana; assim, o município apresenta uma densidade demográfica de 16,9 hab./ $\mathrm{km}^{2}$ e temperatura média anual de $31^{\circ} \mathrm{C}$ (IBGE, 2010). Conforme PNUD (2013) a maior parte do território do Baixo Jequitinhonha apresenta o clima do tipo Tropical Semiúmido, marcado pela sazonalidade da precipitação, estando esta concentrada no verão.

A cidade apresenta-se como polo principal entre os 16 municípios do Baixo Jequitinhonha, desempenhando uma importante função comercial e educacional com a presença do Instituto Federal de Ensino e algumas Faculdades privadas. Mesmo com o crescente setor de serviços, impulsionado nos últimos anos principalmente pelos programas sociais do governo e o tradicional comércio de produtos agropecuários, a renda média da população $(\mathrm{R} \$ 419,98)$ ainda ocupa a posição de número 3.254 no país (PNUD, 2013).

De acordo com os dados apresentados no Plano Diretor da Cidade (2008), em Almenara ocorrem quatro regiões fitofisionômicas, dentre elas a floresta estacional semidecidual (Mata Atlântica), que ocupa maior parte do município (109.480 ha, 47,77\%), a savana (cerrado sensu stricto, 6.624 ha, 2,89\%), a savana gramínea lenhosa (campo cerrado, 63 ha, 0,03\%) e a floresta estacional decidual (caatinga arbórea, 36 ha, 0,02\%), existindo um total de 116.203 ha de flora nativa, correspondendo a 50,70\% da área do município.

A pesquisa foi realizada pelo levantamento total das espécies arbóreas das nove praças existentes na cidade: Praça Acúrcio Lucena, Praça Benício Almeida, Praça Cândido Mares, Praça Leia Fonseca, Praça Hamilton Gonçalves, Praça Hélio Rocha Guimarães, Praça Querubim Otoni, Praça Trazíbulo Torres e Praça Valdir Brito (Figura 1), espaços de importância paisagística, cultural, comercial, lazer, entre outros. 


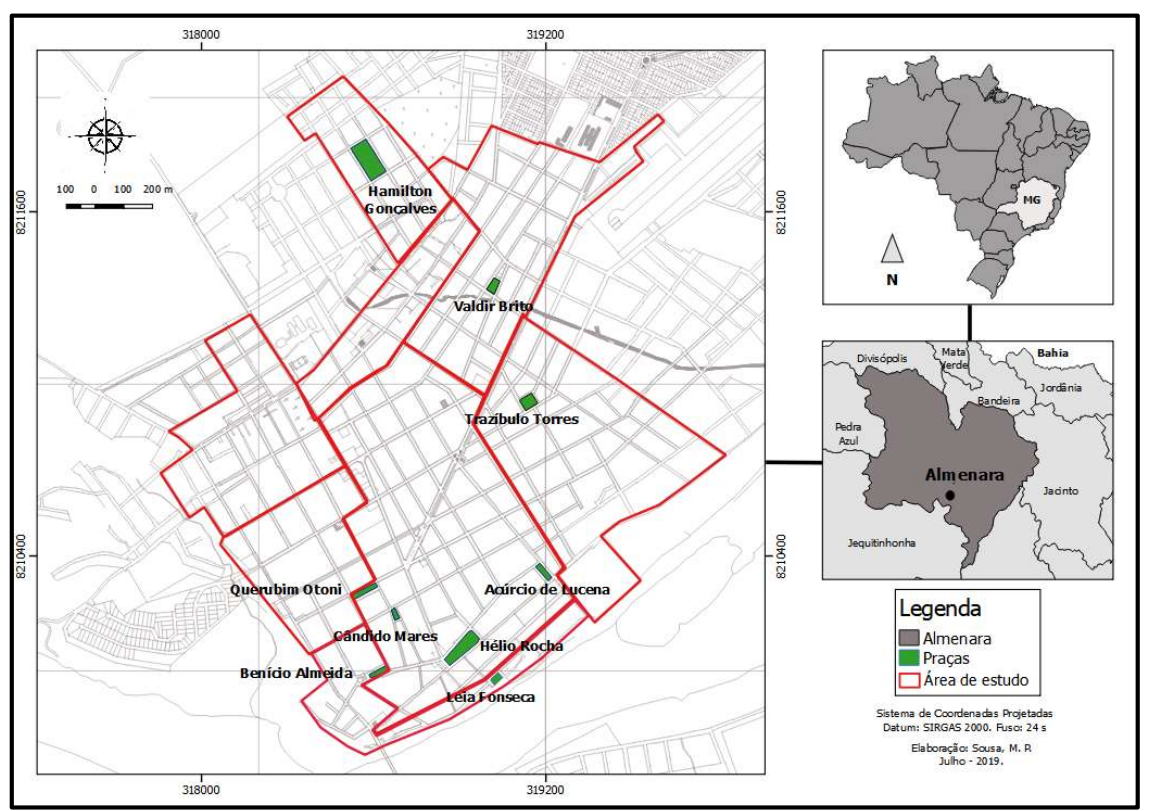

Figura 1. Localização da cidade de Almenara-MG com destaque a localização das praças da cidade em junho de 2019.

A coleta dos dados foi realizada entre os meses de setembro de 2018 e junho de 2019 , com o auxílio de uma ficha técnica, com a descrição dos itens em forma de inventário quali-quantitativo simples de todas as árvores (jovens e adultas), plantadas no interior das praças.

A coleta dos dados foi realizada entre os meses de setembro de 2018 e junho de 2019 , com o auxílio de uma ficha técnica, com a descrição dos itens em forma de inventário quali-quantitativo simples de todas as árvores (jovens e adultas), plantadas no interior das praças. Para este estudo, apenas árvores com altura total mínima de dois metros foram selecionadas, visto que, com esta idade, já estão consolidadas no ambiente.

As informações como a origem e porte das espécies, condição sanitária e dados dendrométricos (diâmetro à altura do peito, diâmetro da copa, altura total das árvores e altura da primeira bifurcação) foram registradas a fim de se obter indicadores capazes de demostrar a condição da vegetação arbórea, conforme dados levantados por autores (Tabela 1). Dados de espacialização como distância entre árvores, canteiro da árvore, condição do sistema radicular e o aspecto da poda sofrida também foram analisados, a fim de se obter não só a condição da arborização, como também a situação geral das praças.

Para proceder à identificação botânica das árvores, ramos vegetativos e reprodutivos (quando presentes) foram coletados, herborizados e conduzidos ao Herbário Professor Geraldo Carlos Pereira Pinto, da Universidade Federal do Sul da Bahia, para a devida identificação e catalogação.

Todas as árvores encontradas foram fotografadas com a utilização de um aparelho smartphone Samsung Galaxy $\mathrm{J} 6^{\circledR}$ para auxiliar na tabulação das informações e georreferenciadas através das 
coordenadas coletadas com a utilização de um aparelho receptor de satélites do tipo GPS Garmin ${ }^{\circledR}$ Etrex 10

Com base no levantamento quali-quantitativo realizado nas praças, foram calculadas sete váriaveis (Tabela 1).

Tabela 1. Relação das variáveis utilizadas no estudo da arborização urbana de Almenara - MG entre os meses de setembro de 2018 e junho de 2019.

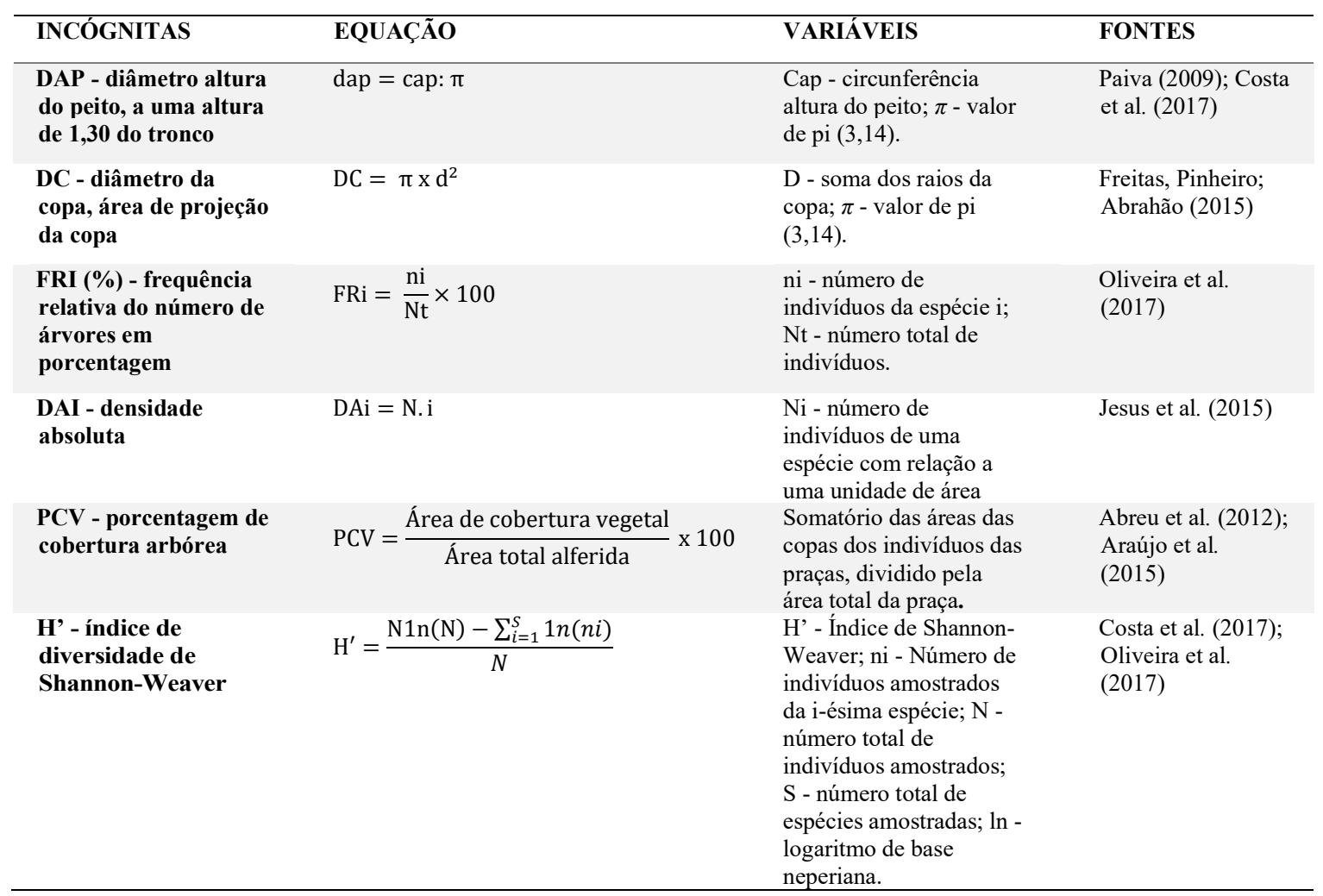

Fonte: Autores, 2019

As categorias de porte das árvores seguiram conforme classificação realizada por Mascaró; Mascaró (2005), sendo: pequeno porte com altura $\leq 6 \mathrm{~m}$ e diâmetro da copa $\leq 4 \mathrm{~m}$; médio porte com altura de $6-10 \mathrm{~m}$, com copa entre $4-6 \mathrm{~m}$; e grande porte com altura $\geq 10 \mathrm{~m}$ e copa com dimensões acima de $6 \mathrm{~m}$.

O diâmetro à altura do peito (DAP) a uma altura de $1,30 \mathrm{~m}$ em relação ao solo foi calculado através da medida de circunferência altura do peito (CAP), que é a medida da circunferência do tronco da árvore em metros, obtida em campo com auxílio da trena. O diâmetro da copa (A) foi obtido através da soma dos raios coletados em campo com auxílio da trena (Tabela 1). A altura da primeira bifurcação foi adquirida em metros no espaço entre o colo da árvore e a primeira inserção de galho; a altura total do indivíduo foi encontrada com o uso do aparelho hipsômetro, marcando o ponto entre o solo e o último galho da copa da árvore.

A distância entre as árvores foi medida com trena, a fim de avaliar supostas competições entre 
as raízes e/ou copas, ou situações que pudessem prejudicar a mobilidade de pedestres.

Para a avaliação da condição físico-sanitária da árvore foram utilizados critérios segundo as classes preconizadas pela Cemig (2011): (1) árvore vigorosa, sem sinais de pragas, doenças ou danos; (2) árvore com vigor médio, podendo apresentar pequenos danos físicos, problemas de pragas ou doenças; (3) árvore em estágio de declínio e com severos danos de pragas, doenças ou físicos; e (4) árvore morta ou com morte iminente.

A medida do canteiro (área livre da planta), foi relacionada ao diâmetro do tronco a 1,3 $\mathrm{m}$ do solo, conforme orientações de São Paulo (2005), em que 0,50 m de DAP deverá corresponder a um canteiro de no mínimo $0,60 \mathrm{~m}$ de largura, de acordo tabela realizada pelo autor. A partir desses dados foi possível avaliar a condição do sistema radicular da árvore, se este ultrapassava o espaço destinado ao colo e as raízes, ou se apresentava afloramento causando danos.

Por fim, foi avaliada a condição de poda das árvores, sendo (1) Sem poda anterior: quando não está evidente que ocorreu a retirada de galhos; (2) Poda de limpeza: poda leve sem causar injúrias ou danos ao indivíduo; e (3) Poda drástica: quando a poda executada desequilibra a árvore, ou quando galhos em excesso foram retirados, provocando injúria mecânica séria na árvore (CEMIG, 2011).

\section{RESULTADOS E DISCUSSÃO}

As praças da cidade de Almenara (MG) apresentam 221 árvores pertencentes a 36 espécies e 16 famílias botânicas. O número de espécies nativas e exóticas da flora brasileira foi de $44 \%$ e $56 \%$ respectivamente (Tabela 2). Segundo Martins e Correia (2016), é comum nos municípios brasileiros ser encontrada uma menor proporção de espécies nativas nos projetos de arborização urbana, o que pode ser justificado pela falta de planejamento e a carência de estudos prévios com as espécies da flora brasileira para ocupação de espaços urbanos (PINHEIRO; MARCELINO; MOURA, 2018).

O maior problema na presença de espécies exóticas no ambiente urbano é que estas podem sair do controle, podendo afetar o funcionamento natural dos ecossistemas e gerar alterações nos processos ecológicos por motivo de sua pressão e agressividade (HOPPEN et al., 2014; PAES, 2016).

Em outros trabalhos de avaliação florística como os de Araújo et al. (2015) em uma praça de Natal - RN, e Souza et al. (2011) nas praças de Aracaju - SE, foram encontrados índices ainda maiores de espécies exóticas (67\% e 58\% respectivamente). Sendo que alguns chegaram a ultrapassar índices superiores a 70\% de espécies exóticas, como na praça do bairro Neópolis (77\%) 
da cidade de Natal-RN (SILVA; ALMEIDA, 2016) e na Praça Barão de Araras (86\%) na cidade de Araras-SP (MARTINS; CORREA, 2016). Situação adversa foi encontrada na cidade de CáceresMT, onde existia um maior número de espécies nativas 58\% (ASSUNÇÃO et al., 2014). Cabe ressaltar que as cidades utilizadas nas respectivas pesquisas são maiores que a cidade alvo deste estudo.

No conjunto das praças amostradas em Almenara, as famílias que representaram maior frequência de espécies foram a Fabaceae (46\%), Bignoniaceae e Myrtaceae (ambas com 17\%). A porcentagem de representantes da família Fabaceae está acima do desejado, pois para efeito de adequado planejamento da arborização urbana, aconselha-se que as espécies arbóreas não ultrapassem mais que 30\% de uma família botânica, sendo essa diversidade essencial para garantir a proteção dessas espécies contra o ataque de pragas e doenças (SANTAMOUR JÚNIOR, 2002). 
Tabela 2. Relação de famílias e espécies identificadas nas nove praças de Almenara - MG e os seus respectivos dados de Origem (proveniência da espécie tendo em conta a flora brasileira). Voucher - Código de identificação do material testemunho depositado no Herbário Professor Geraldo Carlos Pereira Pinto (UFSB). Praças - BA: Benício Almeida, LA: Leila Amaral; AP: Acúrcio Pereira, CM: Candido Mares, HR: Hélio Rocha, QO: Querubim Otoni, TT: Trazíbulo Torres, HG: Hamilton Gonçalves, VB: Valdir Brito; Frequências - FAT: Frequência absoluta total, FR: Frequência relativa.

\begin{tabular}{|c|c|c|c|c|c|c|c|c|c|c|c|c|c|c|c|}
\hline \multirow{2}{*}{ Família } & \multirow{2}{*}{ Nome Científico } & \multirow[b]{2}{*}{ Nome comum } & \multirow[b]{2}{*}{ Origem } & \multirow{2}{*}{ Voucher } & \multicolumn{9}{|c|}{ Praças ( $\mathbf{N}^{\circ}$ de indivíduos) } & \multirow[b]{2}{*}{ FAT } & \multirow[b]{2}{*}{ FR(\%) } \\
\hline & & & & & BA & LA & $\mathbf{A P}$ & CM & HR & QO & TT & HG & $\begin{array}{l}\text { VB } \\
\end{array}$ & & \\
\hline Anacardiaceae & Schinus terebinthifolia Raddi & aroeira-vermelha & Nativa & 700 & & & 1 & & & & & 2 & & 3 & 1,36 \\
\hline Apocynaceae & Nerium oleander $\mathrm{L}$. & espirradeira & Exótica & 675 & 1 & & & & & & & & & 1 & 0,45 \\
\hline \multirow[t]{2}{*}{ Arecaceae } & Dictyosperma album (Bory) H. Wendl. \& Drude ex Scheff. & palmeira princesa & Exótica & 702 & & & & & 4 & & & & & 4 & 1,81 \\
\hline & Dypsis lutescens (H. Wendl.) Beentje \& Dransf. & palmeira areca & Exótica & 697 & 1 & & 7 & & 1 & & & & & 9 & 4,07 \\
\hline \multirow[t]{3}{*}{ Bignoneaceae } & Handroanthus chrysotrichus (Mart. ex DC.) Mattos & ipê amarelo do cerrado & Nativa & 685 & & & & & & & & 2 & & 2 & 0,90 \\
\hline & Handroanthus impetiginosus (Mart. ex DC.) Mattos & ipê rosa & Nativa & 740 & & & & & 6 & & 1 & 9 & & 16 & 7,24 \\
\hline & Tabeluia rosealba (Ridl.) Sandwith. & ipê-branco & Nativa & 717 & 2 & & & & & & & 3 & & 5 & 2,26 \\
\hline Chrysobalanaceae & Licania tomentosa (Benth.) Fritsch & oiti & Nativa & 681 & 1 & & & 5 & 26 & 2 & 1 & 2 & 1 & 38 & 17,19 \\
\hline Combretaceae & Terminalia catappa $\mathrm{L}$. & amendoeira-da-praia & Exótica & 716 & & 1 & & 1 & & 1 & & 2 & 2 & 7 & 3,17 \\
\hline Euphorbiaceae & Joannesia princeps Vell. & cotieira & Nativa & 712 & & & & & & & 1 & & & 1 & 0,45 \\
\hline \multirow[t]{16}{*}{ Fabaceae } & Acacia mangium Willd. & cassia manja & Exótica & 674 & & & & & & & & 2 & & 2 & 0,90 \\
\hline & Adenanthera pavonina $\mathrm{L}$. & olho-de-pavão & Exótica & 729 & & & & & & & & 1 & 1 & 2 & 0,90 \\
\hline & Albizia lebbeck (L.) Benth. & coração-de-negro & Exótica & 725 & & 2 & & & & & & & & 2 & 0,90 \\
\hline & Bauhinia variegata $\mathrm{L}$. & pata-de-vaca-rosa & Exótica & 687 & & & & & & 1 & & & & 1 & 0,45 \\
\hline & Cassia fistula $\mathrm{L}$. & chuva-de-ouro & Exótica & 698 & & 1 & 3 & & & & 1 & 2 & & 7 & 3,17 \\
\hline & Cassia grandis $\mathrm{L}$. & cássia-rosa & Nativa & 699 & & & 1 & & & & & & & 1 & 0,45 \\
\hline & Clitoria fairchildiana R.A. & sombreiro & Nativa & 714 & & & & & & & & & 2 & 2 & 0,90 \\
\hline & Delonix regia (Bojer ex Hook.) Raf. & flamboyant & Exótica & 721 & 1 & & & & & & 1 & 5 & & 7 & 3,17 \\
\hline & Inga edulis Mart. & ingá-de-metro & Nativa & 736 & & & & & & & 1 & & & 1 & 0,45 \\
\hline & Libidibia ferrea (Mart. ex Tul.) L.P. Queiroz & pau-ferro & Nativa & 720 & & & & & & & & 1 & & 1 & 0,45 \\
\hline & Paubrasilia echinata (Lam.) E. Gagnon, H. Lima \& G.P. Lewis & pau-brasil & Nativa & 705 & & & 1 & & 1 & 2 & & 1 & & 5 & 2,26 \\
\hline & Poincianella pluviosa (DC.) L.P. Queiroz & sibipiruna & Nativa & 690 & 6 & & 7 & & & 1 & 10 & & 2 & 26 & 11,76 \\
\hline & Prosopis juliflora Sw. (DC) & algaroba & Exótica & 706 & & & & 1 & 5 & 2 & & & & 8 & 3,62 \\
\hline & Samanea tubulosa (Benth.) Barneby \& J.W.Grimes. & sete-cascas & Nativa & 719 & 1 & & & & & 1 & 4 & 1 & & 7 & 3,17 \\
\hline & Senna multijuga (Rich.) H. S. Irwin \& Barneby & senna & Nativa & 683 & & & 1 & & & & 3 & 15 & & 19 & 8,60 \\
\hline & Tamarindus indica $\mathrm{L}$. & tamarindeiro & Exótica & 709 & & & & & 2 & & & & & 2 & 0,90 \\
\hline Lecythidaceae & Couroupita guianensis & abricó-de-macaco & Nativa & 707 & & & & & 1 & & & & & 1 & 0,45 \\
\hline Lythraceae & Lagerstroemia indica $\mathrm{L}$. & resedá & Exótica & 680 & & & & & & 1 & & & & 1 & 0,45 \\
\hline Malvaceae & Pachira aquatica (DC.) L.P. Queiroz & monguba & Nativa & 689 & & 1 & & & & & & & & 1 & 0,45 \\
\hline Meliaceae & Azadirachta indica A. Juss. & neem-indiano & Exótica & 678 & & & & 1 & & & 4 & 2 & & 7 & 3,17 \\
\hline Moraceae & Ficus benjamina $\mathrm{L}$. & ficus & Exótica & 701 & 2 & & 1 & & & & 10 & 2 & 1 & 16 & 7,24 \\
\hline Moringaceae & Moringa oleifera Lam. & moringa & Exótica & 723 & & 1 & & & & & 2 & 1 & & 4 & 1,81 \\
\hline \multirow[t]{3}{*}{ Myrtaceae } & Melaleuca $\mathrm{cf}$ linariifolia $\mathrm{Sm}$. & melaleuca & Exótica & 703 & & & & & 1 & & & & & 1 & 0,45 \\
\hline & Psidium guajava $\mathrm{L}$. & goiabeira & Exótica & 676 & 1 & 1 & & & & & & & & 2 & 0,90 \\
\hline & Syzygium jambolanum (Lam.) DC. & jambolão & Exótica & 694 & & & & & & & & 2 & & 2 & 0,90 \\
\hline Rutaceae & Murraya paniculta (L.) Jacq. & murta & Exótica & 692 & & 7 & & & & & & & & 7 & 3,17 \\
\hline TOTAL & & & & & 16 & 14 & 22 & 8 & 47 & 11 & 39 & 55 & 9 & 221 & 100,00 \\
\hline
\end{tabular}

Fonte: Autores, 2019 
Em todas as praças, as espécies com a maior frequência de árvores foram a Licania tomentosa (oiti), Poincianella pluviosa (sibipiruna) e Senna cf. simea (sena) (17\%, 12\% e 9\%) respectivamente. Outro caso de adequação é para a espécie de oiti, que é amplamente utilizada na arborização de praças urbanas, especialmente na praça Hélio Rocha (55\%), que segundo Redin et al., (2010), por razões estéticas e fitossanitárias, estas não deveriam ter ultrapassado $15 \%$ de espécies na proporcionalidade do uso em relação ao total de árvores que foram plantadas.

Essa desproporção encontrada entre as árvores da cidade de Almenara pode ter sido motivada pela participação espontânea da população na implantação da arborização, bem como pela produção e doação de mudas de oiti, sibipiruna e sena feitas pelo viveiro municipal, o que influenciou em um número de árvores de espécies nativas quando comparado às exóticas (58\%) (Tabela 2).

A média no índice de diversidade de Shannon-Weiner encontrado em todas as praças da cidade foi de 1,79 nats/ind (Tabela 3). Os menores índices foram encontrados nas praças Cândido Mares (1,07 nats/ind) e na Praça Hélio Rocha Guimarães (1,50 nats/ind), onde nessa última justifica-se pela alta frequência de árvores da espécie oiti.

Os maiores índices encontrados foram das praças Hamilton Gonçalves, Querubim Otoni e Trazíbulo Torres, (2,47, 2,14 e 2,08 nats/ind respectivamente) (Tabela 3). Conforme Silva (2012), valores de Shannon-Weiner abaixo de 2,0 nats/ind refletem baixa diversidade, enquanto valores superiores a 5,0 nats/ind indicam alta diversidade.

Tabela 3. Fatores fitossociológicos encontrados na arborização das praças de Almenara-MG. (Nesp Número de espécies; Narv - Número de árvores; ACV - Área de cobertura arbórea; Área - Área da praça; $\mathrm{DA}_{\mathrm{i}}$ - Densidade absoluta; PCV - Porcentagem de cobertura arbórea; H' - Índice diversidade de ShannonWeiner; Afund - Ano de fundação).

\begin{tabular}{|c|c|c|c|c|c|c|c|c|}
\hline Praça & $\begin{array}{l}\text { Nesp } \\
\text { (und) }\end{array}$ & $\begin{array}{l}\text { Narv } \\
\text { (und) }\end{array}$ & $\operatorname{ACV}\left(\mathrm{m}^{2}\right)$ & Área $\left(\mathrm{m}^{2}\right)$ & $\begin{array}{c}\mathbf{D A}_{\mathbf{i}} \\
\text { (ind/ha) }\end{array}$ & $\begin{array}{l}\text { PCV } \\
(\%) \\
\end{array}$ & $\begin{array}{c}\mathbf{H}^{\prime} \\
\text { (nats/ind) }\end{array}$ & AFund \\
\hline Acúrcio de Lucena & 8 & 22 & 974 & 1278 & 172 & 76 & 1,70 & 1973 \\
\hline Benício Almeida & 9 & 16 & 733 & 1216 & 131 & 60 & 1,93 & 1969 \\
\hline Cândido Mares & 4 & 8 & 760 & 704 & 113 & 108 & 1,07 & 1965 \\
\hline Leia Amaral & 7 & 14 & 504 & 871 & 160 & 58 & 1,56 & 1950 \\
\hline Hamilton Gonçalves & 18 & 55 & 1962 & 8653 & 63 & 23 & 2,47 & 1992 \\
\hline Hélio R. Guimarães & 9 & 47 & 6230 & 5746 & 82 & 108 & 1,50 & 1938 \\
\hline Querubim Otoni & 8 & 11 & 1618 & 1699 & 65 & 95 & 2,14 & 1956 \\
\hline Trazíbulo Torres & 12 & 39 & 1275 & 2182 & 178 & 58 & 2,08 & 1989 \\
\hline Valdir Brito & 6 & 9 & 662 & 1407 & 64 & 47 & 1,73 & 1977 \\
\hline
\end{tabular}

O maior índice (H') encontrado entre os autores pesquisados foi o de Romani et al., (2012) em trabalho realizado em uma praça de Ribeirão Preto - SP (3,14 nats/ind). Na sequência vieram Oliveira et al., (2017) em Aldeias Altas, município de pequeno porte, com 2,43 nats/ind, e Costa et al., (2017) em Caxias com 2,75 nats/ind ambos no Estado do 
Maranhão. Valores considerados também medianos.

É muito comum na maioria das praças brasileiras o emprego de uma arborização com baixa riqueza de espécies. Isto pode acarretar diminuição de biodiversidade e obstruir a visita e permanência de espécies da fauna em áreas urbanas, pois não encontrarão abrigos nem fonte de alimentação (BRUN, et al., 2007). Das principais funções da infraestrutura verde urbana estão a criação e melhoria da qualidade de habitats, corredores ecológicos e a permeabilidade da paisagem (COSTA, 2016).

Face ao exposto, é importante recomendar, para os próximos plantios nas praças da cidade de Almenara, espécies que ainda não foram utilizadas, como Schinus molle L. "aroeira salsa", Tibouchina granulosa (Desr.) Cogn. "quaresmeira" e Peltophorum dubium (Spreng.) Taub. "canafístula", e/ou aquelas que estão adaptadas e que de preferência sejam nativas do Brasil (Libidibia ferrea "pau-ferro", Paubrasilia echinata "pau-brasil", Handroanthus chrysotrichus "ipê-amarelo do cerrado"). Com isso esses espaços podem se tornar mais atrativos à fauna silvestre e ainda melhorar a concepção paisagística (SILVA, 2012).

A DAi encontrada foi de 114 árvores por hectare, área total das praças de 2,38 ha (Tabela 3). Portanto, a média de DAi melhor representada foi da Praça Trazíbulo Torres, com $178 \mathrm{ind} /$ ha, abaixo da maior densidade encontrada entre as praças avaliadas por Jesus et al. (2015) no município de Nossa Senhora do Socorro - SE, com 209,85 ind/ha.

A Praça Hamilton Gonçalves foi a que apresentou menor densidade, com 63 ind/ha. Nessa praça foram encontradas 55 árvores, sendo em sua maioria aparentemente jovens por se tratar da praça mais nova, fundada em 1992 conforme documento apresentado pela Secretaria de Administração do município.

A maioria (69\%) das espécies encontradas nas praças da cidade são de grande porte, com média de altura total de $8,50 \mathrm{~m}$. Utilizando o mesmo critério de classificação, Martins; Correa (2016) obtiveram resultados semelhantes em Araras-SP, com 88,40\% das árvores encontradas nas praças de grande porte (Tabela 4). 
Tabela 4. Relação dos dados dendrométricos das espécies que apresentaram maior abundância de árvores encontradas nas praças de Almenara - MG. Tais como, Narv: Número de árvores; Darv: Distância entre árvores; Harv: Altura média das árvores; Hbif: Altura média da primeira bifurcação das árvores; DAP: Diâmetro médio altura do peito; ACo: Área média da copa.

\begin{tabular}{lcccccc}
\hline Espécie & $\begin{array}{c}\text { Narv } \\
(\mathbf{U n})\end{array}$ & $\begin{array}{c}\text { Darv } \\
(\mathbf{m})\end{array}$ & $\begin{array}{c}\text { Harv } \\
(\mathbf{m})\end{array}$ & $\begin{array}{c}\text { Hbif } \\
(\mathbf{m})\end{array}$ & $\begin{array}{c}\text { DAP } \\
(\mathbf{m})\end{array}$ & $\begin{array}{c}\text { ACo } \\
\left(\mathbf{m}^{\mathbf{2}}\right)\end{array}$ \\
\hline Oiti [Licania tomentosa (Benth.) Fritsch] & 38 & 10,21 & 14 & 1,38 & 0,53 & 152,08 \\
Sibipiruna [Poincianella pluviosa (DC.) L.P. Queiroz] & 26 & 7,64 & 10 & 1,42 & 0,88 & 47,14 \\
Senna [Senna cf. simea (Lam.) H.S. Irwin \& R. Barneby] & 19 & 6,77 & 7 & 1,56 & 0,21 & 52,48 \\
Ficus [Ficus benjamina L.] & 16 & 7,61 & 7 & 0,97 & 0,23 & 53,08 \\
Ipê rosa [Handroanthus impetiginosus (Mart. ex DC.) Mattos] & 16 & 12,03 & 6 & 1,61 & 0,18 & 56,56 \\
Demais espécies & 106 & 9,01 & 7 & 1,23 & 0,22 & 47,20 \\
\hline Média Geral & $\mathbf{3 7}$ & $\mathbf{8 , 8 8}$ & $\mathbf{9}$ & $\mathbf{1 , 4 0}$ & $\mathbf{0 , 3 8}$ & $\mathbf{6 8 , 0 9}$ \\
\hline
\end{tabular}

A área média da copa foi de $68,09 \mathrm{~m}^{2}$, sendo a espécie Prosopis juliflora (algaroba) com maior média geral de projeção de copa, com 235,11 $\mathrm{m}^{2}$. Porém daquelas espécies com maior frequência de árvores, a maior média ficou com a espécie Licania tomentosa (oiti), com 152,08 $\mathrm{m}^{2}$, espécie de grande porte e que apresenta ampla projeção de copa (Tabela 4). Como essa espécie foi a de maior dominância na Praça Hélio Rocha Guimarães, consequentemente foi a praça que obteve maior PCV (108,42\%). A de menor porcentagem foi a Praça Valdir Brito (47,05\%), que possui a quinta maior área $(1.406,57$ $\mathrm{m}^{2}$ ), porém conta com o menor número de árvores (Figura 3).

Dessa forma, admitindo os benefícios que a cobertura arbórea proporciona a esses ambientes, podemos assegurar a necessidade de plantio de espécies que representam as maiores projeções de copa nas praças reconhecidas nesta pesquisa como as mais carentes desse atributo.

Sobre a altura da primeira bifurcação, todas as praças apresentaram a média abaixo do adequado (acima de $1,80 \mathrm{~m}$ ) e apenas $26 \%$ de todas as árvores possuíam valores superiores (Tabela 4). A praça com a menor média é a Praça Leia Fonseca $(0,60 \mathrm{~m})$ e justifica-se pela maior frequência das árvores da espécie Murraya paniculta (murta), que além de exótica, não forma tronco definido e pode não ter recebido tratos culturais necessários, como podas de condução e limpeza.

A média de DAP entre as espécies é de $0,38 \mathrm{~m}$, com melhor resultado para a espécie Poincianella pluviosa (sibipiruna) (0,88 m) (Tabela 4). Quanto à avaliação por indivíduo, foram constatados $29 \%$ com um valor de medida abaixo de $0,15 \mathrm{~m}$, isso pode inferir que essa situação é influenciada pela existência de espécies de pequeno porte (Praça Leia Fonseca), ou pode se tratar de espécies introduzidas recentemente (Praça Hamilton Gonçalves). Com isso, é razoável que a primeira possa receber a implantação de novas 
espécies de médio e grande porte para que os frequentadores possam usufruir de melhor sombreamento. A segunda, por sua vez, deve receber atenção na proteção dessas árvores, com o uso de tutores e grades de proteção visando o livramento de ações de vandalismo, depredação e consequentes perdas por acidentes naturais.

Sobre o aspecto fitossanitário das árvores encontradas nas praças, os resultados demonstraram que $86 \%$ estavam vigorosas, sem sinais de pragas ou doenças e/ou com vigor médio, apresentando pequenos danos físicos, algum sinal de pragas e doenças. Cerca de $14 \%$ foram encontradas em estágio de declínio, com severos danos motivados por podas irregulares, pragas, doenças e injúrias provocadas por moradores. Apenas um indivíduo foi encontrado morto (Figura 2B).

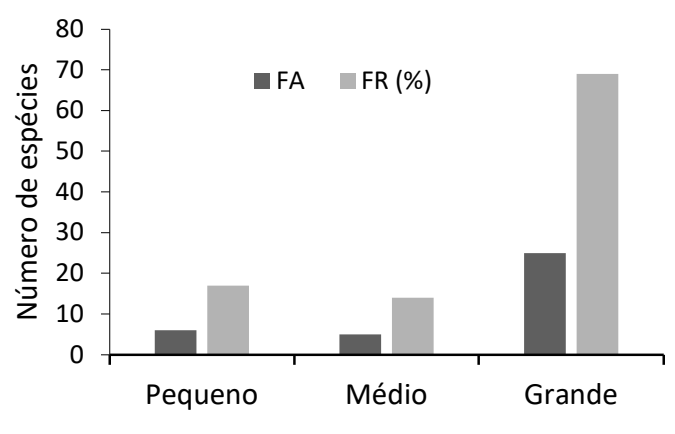

a.

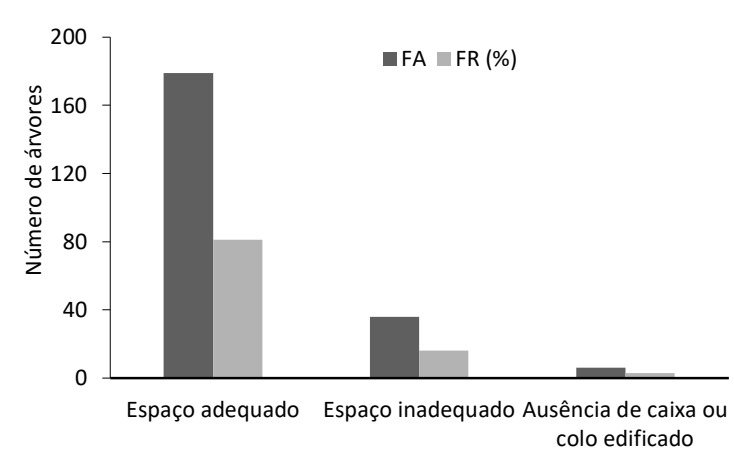

c.

Figura 2. a. Avaliação do porte; b. Avaliação da condição fitossanitária das árvores; c. Avaliação da condição do espaço livre; d. Avaliação da condição do sistema radicular das árvores encontradas nas praças de Almenara - MG.

A Praça Trazíbulo Torres e a Praça Leia Fonseca foram os locais com maior número de árvores doentes, com $18 \%$ e $43 \%$ respectivamente. O manejo de poda e o controle fitossanitário são recomendados nesses casos, bem como a promoção de ações educativas visando à redução de danos ao patrimônio público.

Sousa e et al, 2020

ISSN 0104-5490 
Quanto à condição do espaço livre da árvore, 19\% estavam posicionadas em espaço inadequado, sem presença de área livre para a árvore (canteiro), ou apresentava-se com colo edificado (Figura 2C). O canteiro destinado à árvore deve corresponder ao diâmetro do tronco a 1,3 $\mathrm{m}$ do solo e ao local do plantio, que pode variar entre 0,70 $\mathrm{m}$ e 1,20 $\mathrm{m}$ de largura. Caso essas medidas sejam contrariadas, as árvores podem apresentar afloramento de raízes fora do canteiro e causar danos no local prejudicando o trânsito de pedestres, cadeirantes e deficientes visuais (SÃO PAULO, 2005).

A Praça Hélio Rocha Guimarães foi o local com maior número de danos às vias de passagem de pedestres, causados principalmente pelas espécies Prosopis juliflora (algaroba) e Licania tomentosa (oiti). Nas praças de Alagoinhas-BA, foram encontradas raízes superficiais em parte das árvores implantadas (43\%), porém nem todas apresentavam danos ao ambiente inserido, pois algumas delas estavam em local de muito espaço, sem calçamento ou edificação (VAZ; ROCABADO, 2018).

A média de distância encontrada entre árvores foi de $8,88 \mathrm{~m}$ (Tabela 4), considerada razoável levando em consideração a média aritmética entre os portes recomendada por São Paulo (2005), que é a soma de 5,00 m; 8,00 m e 10,00 m, totalizando 23,00 m divididos por três com resultado de 7,66 m, e assim facilitando a comodidade e a mobilidade entre os frequentadores da praça.

Quanto ao aspecto da poda sofrida, foi observado que 26 das 221 árvores estavam em estado de declínio provocando o seu desequilíbrio motivado pela poda (Figura 3a e b). A maior incidência ocorreu na Praça Hamilton Gonçalves, com mais de $46 \%$ dos casos. Tal situação indica que a população pode ter realizado práticas de poda na praça sem o conhecimento e autorização da prefeitura, embora esteja descrito no Código de Posturas da cidade, Lei $\mathrm{n}^{\mathrm{o}}$ 612, Art. 46, que a poda é um serviço de exclusividade da prefeitura (Pma, 1990), que além de configurar crime ambiental previsto na Lei de Crimes Ambientais (Lei ${ }^{\circ}$ 9.608/1998), pode oferecer risco à integridade física daquele que não passou por treinamento adequado à função. 
Figura 3: Danos causados a árvore em decorrência da poda malconduzida na Praça Hamilton Gonçalves em Almenara-MG: a. senna (Senna cf. simea (Lam.) H.S. Irwin \& R. Barneby); b. pau-brasil (Paubrasilia echinata (Lam.) E. Gagnon, H. Lima \& G.P. Lewis).
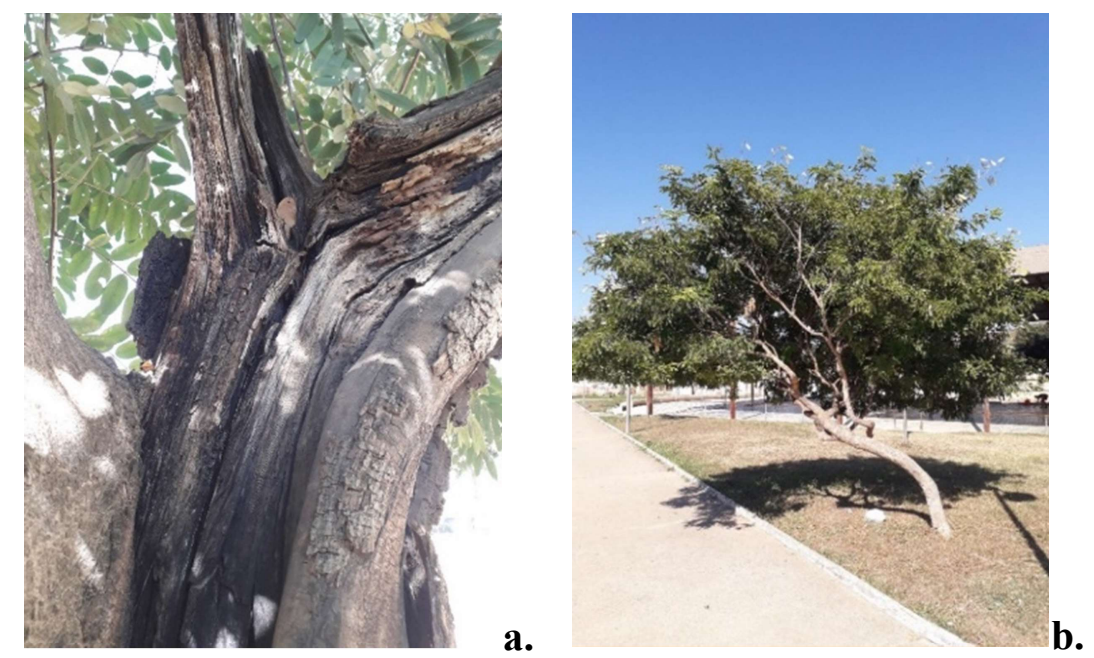

Fonte: Acervo particular do autores (junho de 2019).

Das demais árvores, 91 sofreram podas leves consideradas de limpeza e/ou de condução da copa, e 104 não apresentavam nenhum sinal de que foram retirados galhos da árvore. Muitas vezes o declínio na saúde da árvore pode ser verificado com o manejo. Dessa maneira, a sanidade das árvores e a poda estão, na maioria das vezes, bastante alinhados, já que as árvores doentes e infectadas por pragas podem ter sofrido podas que provocaram lesões e escoriações, deixando fissuras que desencadearam o dano (OLIVEIRA, 2012).

Destaca-se que podas irregulares, aquelas em que não foram verificadas a arquitetura da copa nem suas exigências ecológicas, podem causar sérios danos à estrutura da árvore, influenciando drasticamente sua fisiologia, trazendo graves consequências à sanidade do indivíduo arbóreo (CEMIG, 2011; VAZ; ROCABADO, 2018).

A falta de planejamento gera danos e prejuízos ao erário público e às espécies, que podem estar intimamente relacionados às incompatibilidades existentes entre as árvores e os equipamentos e instrumentos urbanos, produzindo os chamados conflitos (BIONDI, 2015). O planejamento da arborização deve ser pensado de acordo com as necessidades locais e especificidades da flora do ambiente, com iniciativas voltadas a realidade de cada local, caso contrário a arborização ainda pode ser vista apenas como elemento estético no cenário urbano, que não inclui a população como principal beneficiária (DUARTE et al., 2017). 
Dessa forma, estudos orientados ao conhecimento das espécies arbóreas utilizadas na arborização urbana, como praças e avenidas, colaboram de modo direto com informações que possam suplementar a administração pública no gerenciamento, planejamento e manutenção desses espaços, de forma a atender os princípios socioambientais na implantação e gestão das espécies nas cidades (OLIVEIRA et al., 2017).

\section{CONCLUSÕES}

O diagnóstico da arborização das praças de Almenara-MG demonstrou que, de forma geral, as praças oferecem boa condição ambiental e paisagística aos seus frequentadores, nos aspectos de cobertura arbórea, densidade e diversidade florística. Porém, sob o ponto de vista individual, algumas praças contam com uma arborização que apresentam sinais de deficiência no planejamento arbóreo (Praça Hamilton Gonçalves, Praça Querubim Otoni e Praça Valdir Brito); baixas porcentagens de cobertura arbórea (Valdir Brito); baixos índices de diversidade (Praça Cândido Mares e Praça Hélio Rocha Guimarães); e problemas fitossanitários (Praça Leia Fonseca e Praça Trazíbilo Torres).

Diante dos dados expostos, podemos sugerir à gestão pública municipal, o plantio de novas espécies em todas as praças que apresentaram índices baixos de densidade arbórea, a fim de suprir essa carência com a indicação daquelas que além de possuírem melhor projeção de copas, como é o caso do oiti e da sibipiruna, outras que possam favorecer as funções paisagísticas, como é o caso da Cassia grandis L. (cassia-rosa); ecológicas, que podem proporcionar melhor interação avifauna, como a espécie Inga edulis Mart. (ingá-de-metro); e culturais como o Handroanthus chrysotrichus (Mart. ex DC.) Mattos (ipê-amarelo-do- cerrado).

Para melhor organização dessas ações é imprescindível que a prefeitura de Almenara providencie um plano de arborização urbana para o município. A fim de propor o planejamento adequado, indicando técnicas e locais de plantio, escolha das espécies adequadas, práticas e manutenção de boas podas, e tratos culturais das espécies já implantadas; para que os conflitos existentes sejam mitigados para que a vegetação urbana possa proporcionar todos os benefícios a ela atribuídos. 


\section{REFERÊNCIAS}

ALCANTARA, M. A. DOS R.; VAZQUEZ, G. H. Caracterização paisagística e da frequência de usuários de duas praças centrais de Caraguatatuba/SP. RevSbau, Piracicaba - SP, v. 10, n. 3, p. 38-59, 2015.

ALI-KHODJA, A. Amenagement urbain: La problematique de l'espace vert public dans la ville de Constantine. Sciences \& Technologie D, $\mathrm{n}^{\mathbf{0}}$ 32, Université Mentouri Constantine, Algérie, 2010, pp. 9-18.

ARAÚJO, L. H. B. D.; NÓBREGA, C. C. D.; SILVA, A. C. F. D.; VIEIRA, F. D. A. Análise quali-quantitativa da arborização da Praça Pedro Velho, Natal, RN. Agropecuária Científica no Semiárido, Campina Grande, v. 11, n. 1, p. 65-71, 2015.

ASSUNÇÃO; K. C.; LUZ, P. B.; NEVES, L. G.; SOBRINHO, S. P. Levantamento Quantitativo da arborização de praças da cidade de Cáceres/MT. RevSbau, Piracicaba SP, v.9, n.1, p. 123-132, 2014.

BIONDI, D. Floresta urbana. Curitiba: O autor, 2015.

BRASIL. Lei $\mathrm{n}^{\circ} 9.605$ de 12 de fevereiro de 1998. Lei de Crimes Ambientais. Presidência da República - Casa Civil.

BRUN, F.G.; LINK, D.; BRUN, E.J. O emprego da arborização na manutenção da biodiversidade de fauna em áreas urbanas. RevSbau, Piracicaba - SP. V. 2, n. 1. p. 117$127,2007$.

CEMIG (Companhia Energética de Minas Gerais). Manual de Arborização. Belo Horizonte. Cemig/Fundação Biodiversitas, 2011.

CESSA, R. M. A., Conforto térmico em áreas verdes na cidade de Sorriso-MT. RevSbau, Piracicaba-SP, v.12, n.1, p. 17-30, 2017.

COSTA, C. F.; FONSECA, R. S.; ALMEIDA, D. B.; OLIVEIRA, M. S.; OLIVEIRA, D. S.; BRAGA, J. H. P. Espécies utilizadas na arborização em praças do município de Caxias, Maranhão. RevSbau, Piracicaba, v. 12, n. 1, p. 65-78, 2017.

COSTA, S. A importância das ruas arborizadas para a consolidação da infraestrutura verde pública em áreas urbanas: $\mathrm{O}$ caso da cidade da Guarda. 2016. 58p. Dissertação (Mestrado em Arquitetura paisagista) Faculdade de Ciências da Universidade do Porto.

DUARTE, T. R. P. N.; ANGEOLETTO. F.; RICHARD, E.; VACCHIANO, M. C.; LEANDRO, D. S.; BOHRER, J. F. C.; LEITE, L. B.; SANTOS, J. W. M. C. Arborização urbana no Brasil: um reflexo de injustiça ambiental. Terr@Plural, Ponta Grossa, v.11, 
n.2, p. 291-303, 2017.

GONÇALVES, A.; MENEGUETTI, K. S. Projeto de arborização como patrimônio da idade. Ambiente Construído, Porto Alegre, v. 15, n. 1, p. 99-118, 2015.

HOPPEN, M. I.; DIVENSI, H. F.; RIBEIRO, R. F.; CAXAMBÚ, M. G. Espécies exóticas na arborização de vias públicas no município de Farol-PR, Brasil. Revista da Sociedade Brasileira de Arborização Urbana, Piracicaba-SP, v. 9, n. 3, p.173-186, 2014.

IBGE- Instituto Brasileiro de Geografia e Estatística. CENSO 2010. (acesso em 20 out 2018). Disponível em: https://censo2010.ibge.gov.br/noticias-censo

IMAM, AUK \& BANERJEE, UK Ambio (2016). Urbanisation and greening of Indian cities: Problems, practices, and policies. Ambio v. 45, ed. 1, p. 442-457, 2016.

JESUS, J. B., JUNIOR, R. R. V., MELlO, A. A., FERREIRA, R. A. Análise da arborização de praças do município de Nossa Senhora do Socorro - SE. RevSbau, Piracicaba-SP, v. 10, n. 2, p.61-77, 2015.

LIVESLEY, S.J.; MCPHERSON, E.G.; CALFAPIETRA, C. Impacts on Urban Water, Heat, and Pollution Cycles at the Tree, Street, and City Scale. Journal of Environmental Quality - special secTion. J. Environ. Qual. 45, p. 119-124, 2016.

MANFIO, V.; BENADUCE, G. M. C. A (re) estruturação urbana e o desenvolvimento local da pequena cidade de Nova Palma/RS. Revista GEOMAE, Campo Mourão, v. 2, n. 1 p.71-82, 2011.

MARTINS, V. F.; CORREA, G. W. Avaliação da arborização da Praça Barão de Araras (Araras - SP). Revista Ciência, Tecnologia \& Ambiente. v. 4, n. 1, p. 20-29, 2016.

MASCARÓ, L. E. A. R.; MASCARÓ, J. L. Vegetação urbana. 2. ed. Porto Alegre: Mais Quatro Editora, 2005.

OLIVEIRA, A. S.; SANCHES, L.; MUSIS, C. R.; NOGUEIRA, M. C. J. A. Benefícios da arborização em praças urbanas - o caso de Cuiabá/MT. Revista Eletrônica em Gestão, Educação e Tecnologia Ambiental, v. 9, n. 9, p. 1900-1915, 2013.

OLIVEIRA, G.N. Revitalização da Arborização Urbana no Centro de Governador Valadares-MG. Lavras-MG, 2012.

OLIVEIRA, M. S., FERREIRA, A. W. C., LOPES, J. R. S., REIS, J. R., JUNIOR, W. R. S., COSTA, J. A. Espécies vegetais presentes em praças e avenidas no município de Aldeias Altas, Maranhão, Brasil. RevSbau, Piracicaba-SP, v.12, n. 4, p.13-22, 2017.

PAES, M. P. Plantas exóticas invasoras no Brasil: uma ameaça às plantas nativas e ao ecossistema. Revista Especialize On-line IPOG - Goiânia - Edição nº 11 Vol. 01/ 2016. 
PAGLIARI, S. C.; DORIGON, E. B. Arborização urbana: importância das espécies adequadas. 2013. Revista Unoesc e Ciência - ACET, Joaçaba, v.4, n.2, 139-148, 2013. PINHEIRO, R. T.; MARCELINO, D. G.; MOURA, D. R. Espécies arbóreas de uso múltiplo e sua importância na conservação da biodiversidade nas áreas verdes urbanas de Palmas, Tocantins. DeMA. Desenvolv. Meio Ambiente, v. 49, p. 264-282, 2018. PNUD - PROGRAMA DAS NAÇÕES UNIDAS PARA O DESENVOLVIMENTO. Atlas do desenvolvimento humano no Brasil. Brasília: PNUD, IPEA, FJP, 2013. Disponível em: http://www.atlasbrasil.org.br/2013. REDIN, C. G,; VOGEL, C,; TROJAHN, C. D. P,; GRACIOLI, C. R,; LONGHI, S. J. Análise da arborização urbana em cinco praças do município de Cachoeira do Sul, RS. RevSbau - SP. v.5, n. 3, p. 149-164, 2010.

RIVELINI, P. M.; GOMES, M. F. Análise da arborização viária e sua relação com a infraestrutura urbana na Rua Luiz Pereira Barreto, Araçatuba-SP - Revista Contemporânea: Revista Unitoledo: Arquitetura, Comunicação, Design e Educação, v. 02, n. 01, p. 88-103, 2017.

ROMANI, G. N., GIMENES, R., SILVA, M. T., PIVETTA, C. F. L., BATISTA, G. S. Análise quali-quantitativa da arborização na praça XV de Novembro em Ribeirão PretoSP, Brasil. Revista Árvore, Viçosa-MG, v.36, n.3, p. 479-487, 2012.

RUBIRA, F. G. Definição e diferenciação dos conceitos de áreas verdes/espaços livres e degradação ambiental/impacto ambiental. Caderno de Geografia (UNIFAL) AlfenasMG, v.26, n.45, p. 134-150, 2016.

SANTAMOUR JÚNIOR, F.S. Trees for urban planting: diversity uniformity, and common sense. Washington: U.S. National Arboretum, Agriculture Research Service, U.S. Department of Agriculture Washington, D.C. p.57-66, 2002.

SÃO PAULO. Manual técnico de arborização urbana. São Paulo: Secretária do verde e meio ambiente, 2005.

SCHVARSTZHAUPT, C.C; REIS, A. T. Vegetação Urbana e instrumentos legais. Urban Vegetation and Legal Instruments. In: XVII Enanpur - Desenvolvimento, crise e resistência: Quais os caminhos do planejamento urbano e regional? http://anais.anpur.org.br/index.php/anaisenanpur/article/view/2313/2292. São Paulo - SP. p. 1-19, 2017.

SHANAHAN, D. F.; LIN, B.B.; GASTON, K. J.; BUSH, R.; FULLER, R.A. What is the role of trees and remnant vegetation in attracting people to urban parks? 
Landscape Ecol. v. 30, p. 153-165. 2015.

SILVA, C. D. D.; ALMEIDA, L. M. Composição florística e fitossociológica das praças do bairro de Neópolis, Natal-RN. Revista Cultural e Científica do UNIFACEX. v. 14, n. 2, p. 86-103, 2016.

SILVA, R.N. Caracterização e análise quali-quantitativa da arborização em praças da área central da cidade de Arapiraca, AL. RevSbau, Piracicaba - SP. v.7, n.2, p.102-115, 2012. VARGAS, A. M., BALMACEDA, N.. Forestación urbana mediante compensación ambiental. Revista Centro de políticas públicas UC. v. 6 n. 43, p. 1-14, 2011.

VAZ. G. A. S.; ROCABADO. J. M. A. Arborização urbana em praças de Alagoinhas, BA. Ambiência - Guarapuava (PR) v.14 n.3, p. 496 - 512, 2018. 